Tohoku J. Exp. Med., 2003, 199, 161-169

\title{
Current Hair Mercury Levels in Japanese: Survey in Five Districts
}

\author{
Akira Yasutake, Miyuki Matsumoto, Masako Yamaguchi and NOriyuki \\ HACHIYA
}

National Institute for Minamata Disease, Minamata 867-0008

\begin{abstract}
Yasutake, A., Matsumoto, M., Yamaguchi, M. and Hachiya, N. Current Hair Mercury Levels in Japanese: Survey in Five Districts. Tohoku J. Exp. Med., 2003, 199 (3), 161-169 — To understand the current Japanese hair mercury levels, we planned a survey of hair mercury among the general populations of different regions in Japan. The present paper, as the first report of the survey, summarized the results obtained in five districts, Minamata, Kumamoto, Tottori, Wakayama and Chiba. Hair samples were collected at beauty saloons, barbershops and primary schools in each district with questionnaires on age, sex, amount and species of fish usually consumed, hair-dyed and artificial hair waving "permanent wave." The total mercury levels of 3686 hair samples collected were analyzed by an oxygen combustion-gold amalgamation method. The geometric mean of the total mercury concentration was significantly higher in males than in females, i.e., $2.55 \mu \mathrm{g} / \mathrm{g}$ and $1.43 \mu \mathrm{g} / \mathrm{g}$, respectively. The sex difference was also observed on hair samples without artificial waving, i.e., $2.64 \mu \mathrm{g} / \mathrm{g}$ and $1.64 \mu \mathrm{g} / \mathrm{g}$, respectively. The geometric mean in each district varied from 2.23 to $4.79 \mu \mathrm{g} / \mathrm{g}$ for males and from 1.23 to $2.50 \mu \mathrm{g} / \mathrm{g}$ for females. The average hair mercury levels were highest in Chiba among the five districts both in males and females. A multiple regression analysis revealed a significant correlation of the mercury level with age, sex, amount of daily fish consumption, tuna and bonito as usually consumed fish, artificial waving and Chiba as a residential area. In the laboratory experiment, we found that the treatment of hair samples with a lotion for artificial waving caused a 30\%-reduction in the mercury content. Furthermore, longitudinal hair analysis showed a marked difference in the concentration between the hair root and the tip of the hair taken from artificially waved females; higher values were observed at the hair root. These results suggested that artificial waving significantly removes hair mercury and that hair analysis at the hair root should be necessary to estimate an accurate methylmercury exposure for waved persons. hair mercury; Japanese population; age dependency; sex difference; geological difference
\end{abstract}

(C) 2003 Tohoku University Medical Press

Received March 6, 2003; revision accepted for publication March 13, 2003.

Address for reprints: Akira Yasutake, Ph.D., National Institute for Minamata Disease, 4058-18 Hama, Minamata 867-0008, Japan.

e-mail: yasutake@nimd.go.jp 
Human hair is well known as an excellent marker for methylmercury ( $\mathrm{MeHg}$ ) exposure, and its mercury levels have been frequently analyzed in cases of accidental mercury pollution, such as in Minamata and Niigata in Japan, and in Iraq, to estimate human exposure. WHO (1990) has reported, based on the data in Minamata, Niigata and Iraq, that no health effect was observed with hair mercury levels below $50 \mu \mathrm{g} / \mathrm{g}$ for adults. However, since a fetus is most vulnerable to $\mathrm{MeHg}$ toxicity, the report also suggested that the levels of pregnant women should be kept less than $10 \mu \mathrm{g} / \mathrm{g}$. The United States Environmental Protection Agency (EPA 1997) postulated $0.1 \mu \mathrm{g} / \mathrm{kg}$-body weight/day as a reference dose (RfD) of methylmercury, an ingestion dose limit that is considered to cause no adverse health effect to a human, including sensitive subpopulations. Since the EPA's RfD had been based on a benchmark analysis on data from the acute exposed population in Iraq accident (Cox et al. 1989), the United States National Research Council (NRC) reevaluated the RfD level as a scientifically justified level. The NRC (2000) pointed out that its elucidation should be based on the recent data obtained from the cohort study currently conducted in Faroe Islands, Denmark. The EPA's RfD level corresponds to a hair mercury concentration of $1.0 \mu \mathrm{g} / \mathrm{g}$. However, the hair mercury levels of most general populations are expected to be higher than $1.0 \mu \mathrm{g} / \mathrm{g}$ in high fish-consuming countries such as Japan. Accordingly, it would not be adequate to employ the EPA's RfD as it is in Japan. Although it may also be necessary to establish a revised safety exposure limit in Japan, very limited information, such as the current exposure level of mercury among the general population, is available.

We analyzed the hair mercury levels of the general populations in Japan over varying ages. Since the amount and species of fish consumed were expected to be different among the districts in Japan, we selected five sampling areas considering geological characteristics. The analytical results may be useful as a basal data for determination of the critical hair mercury level in Japan.

\section{Materials AND Methods}

\section{Hair sampling}

Hair samples were collected at beauty saloons and barbershops in Minamata, Kumamoto, Tottori, Wakayama and Chiba with questionnaires on fish consumption (amount and species), age, sex, hair-dyed and artificial hair waving "permanent wave" during 2000 to 2002. The hair samples were also collected at a primary school in each district to supply samples from children. The age of the participants was distributed from 0 to 95 , and 92.4\% ranged between the ages of 5 to 74 . This study had been approved by review of the institutional ethical board.

\section{Mercury analysis}

For mercury analysis, the hair samples collected, 0.1 to $1 \mathrm{~g}$ from each person, were washed well with detergent, and rinsed two times with acetone to dry. The dried hair was cut into small pieces $(<2 \mathrm{~mm})$ with scissors. Aliquots of samples (15 to $20 \mathrm{mg}$ ) were dissolved in $2 \mathrm{~N} \mathrm{NaOH}$ with heating at $60^{\circ} \mathrm{C}$ for 1 hour. Ten or twenty $\mu 1$ of the solution was used to analyze the total mercury levels by oxygen combustion-gold amalgamation method using an atomic absorption detector MD-1 (Nippon Instrument, Co., Ltd., Osaka). $2.5 \mathrm{nM}$ mercuric chloride $(0.5 \mu \mathrm{g} \mathrm{Hg} / \mathrm{ml})$ in $0.5 \mathrm{M}$ L-cysteine/ 0 . $2 \%$ bovine serum albumin solution was used as an external standard.

\section{Effects of artificial hair waving}

The effect of artificial waving lotions was examined using hair samples collected from 4 female Minamata citizens who had no artificial hair waving. The hair samples were treated up to 3 times with Volutis Elastine $\mathrm{N}$ (Nippon Loreal, Co., Ltd., Tokyo), a waving lotion com- 
monly used in beauty saloons and barbershops, according to a procedure recommended by the manufacture at 2 to 3 -days intervals. After each treatment, mercury levels in the aliquots (c. a. $1 \mathrm{mg}$ ) of the hair samples were determined directly (without dissolving in $2 \mathrm{~N} \mathrm{NaOH}$ ) using the analyzer mentioned previously. To examine further an effect of the artificial waving on hair mercury level, 10 pieces of whole hair strands were collected from 136 adult women ( $\geqq 20$ years old) in Minamata City with a questionnaire on artificial hair waving. The hair samples thus obtained were adjusted at the roots and cut in 1-cm sections. Mercury levels at each section (0.5 to $1 \mathrm{mg}$ ) were analyzed as mentioned previously.

\section{Statistical analysis}

Because hair mercury concentrations were distributed in a lognormal profile, Student's $t$-test was performed on the mercury content data after logarithmic conversion. Multiple regression analysis was conducted by using a SPSS statistical package (SPSS Japan Inc., Tokyo). The amount of daily intake of total fish and shellish was estimated from the serving frequency of any fish or shellfish and the amount of fish and shellfish consumed in each serving.

\section{RESUlts}

Distributions, range and geometric mean of the mercury level of 3686 hair samples collected in five districts are summarized in Fig. 1 and Table 1. Because the mercury concentrations were apparently distributed in a lognormal manner as shown in Fig. 1, the geometric mean was used as a representative for hair mercury levels instead of the arithmetic mean. Hair mercury concentrations were distributed at a higher range in the total male population $(n=$ 2020) with a geometric mean of $2.55 \mu \mathrm{g} / \mathrm{g}$ than in the total female population $(n=1666)$ with 1 . $43 \mu \mathrm{g} / \mathrm{g}$. If the analysis was restricted within the data from participants without artificial hair waiving, a geometric mean was $1.64 \mu \mathrm{g} / \mathrm{g}$ for females or $2.64 \mu \mathrm{g} / \mathrm{g}$ for males. On the other hand, $1.24 \mu \mathrm{g} / \mathrm{g}$ and $1.97 \mu \mathrm{g} / \mathrm{g}$ were obtained from artificially waved females and males, respectively. The sex difference in the geometric mean was statistically significant on each of

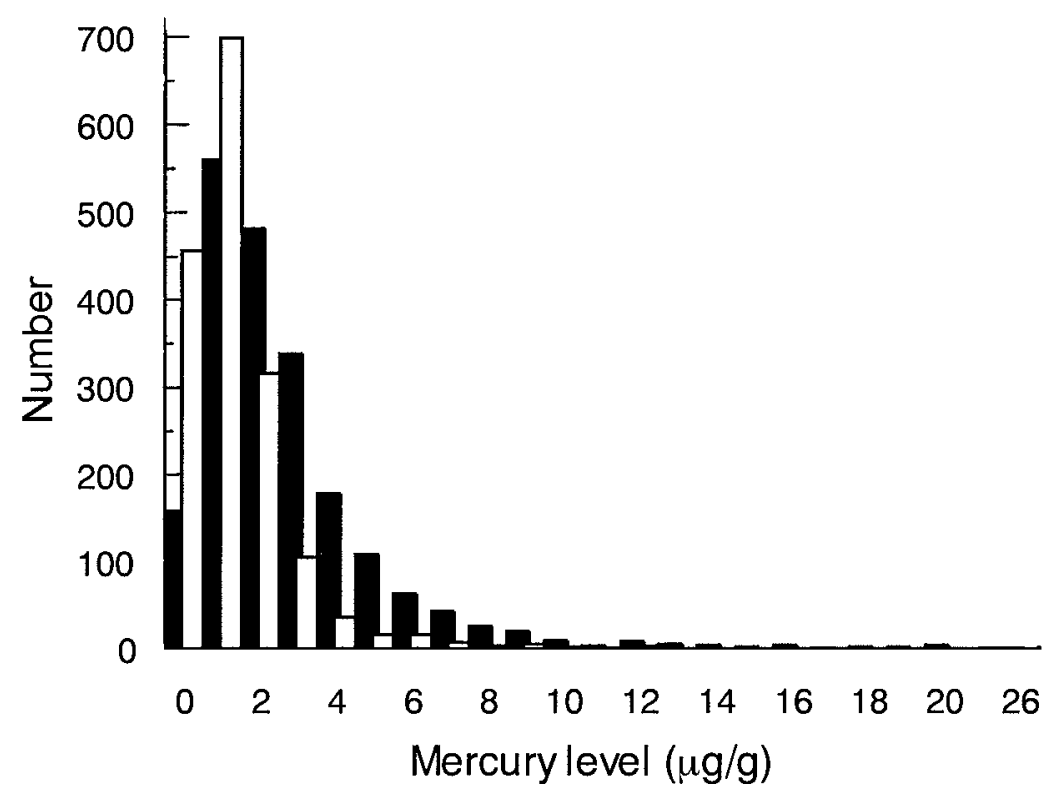

Fig. 1. Distribution of the hair mercury content among the total population. Open bar and solid bar indicate female and male populations, respectively.

口, Male; $\square$, Female. 
TABLE 1. Geometric mean and range of the hair mercury content in five geological populations

\begin{tabular}{|c|c|c|c|c|c|}
\hline \multirow{2}{*}{ Residence } & \multirow{2}{*}{ Sex } & \multirow{2}{*}{$n$} & \multicolumn{3}{|c|}{ Hair mercury content $(\mu \mathrm{g} / \mathrm{g})$} \\
\hline & & & Geometric mean & Min & Max \\
\hline \multirow[t]{3}{*}{ Minamata } & $\mathrm{F}$ & 594 & 1.23 & 0.09 & 7.33 \\
\hline & $\mathrm{M}$ & 344 & 2.39 & 0.22 & 10.56 \\
\hline & Total & 938 & 1.76 & 0.09 & 10.56 \\
\hline \multirow[t]{3}{*}{ Kumamoto } & $\mathrm{F}$ & 327 & 1.33 & 0.14 & 6.20 \\
\hline & $\mathrm{M}$ & 388 & 2.23 & 0.20 & 19.18 \\
\hline & Total & 715 & 1.57 & 0.14 & 19.18 \\
\hline \multirow{3}{*}{ Tottori } & $\mathrm{F}$ & 209 & 1.40 & 0.26 & 12.52 \\
\hline & $\mathrm{M}$ & 616 & 2.32 & 0.00 & 10.21 \\
\hline & Total & 825 & 2.04 & 0.00 & 12.52 \\
\hline \multirow[t]{3}{*}{ Wakayama } & $\mathrm{F}$ & 303 & 1.46 & 0.00 & 8.09 \\
\hline & $\mathrm{M}$ & 417 & 2.32 & 0.10 & 20.66 \\
\hline & Total & 720 & 2.04 & 0.00 & 20.66 \\
\hline \multirow[t]{3}{*}{ Chiba } & F & 233 & 2.30 & 0.14 & 25.75 \\
\hline & $\mathrm{M}$ & 255 & 4.79 & 0.26 & 26.76 \\
\hline & Total & 488 & 3.37 & 0.14 & 26.76 \\
\hline \multirow[t]{3}{*}{ Total } & $\mathrm{F}$ & 1666 & 1.43 & 0.00 & 25.75 \\
\hline & $\mathrm{M}$ & 2020 & 2.55 & 0.00 & 26.76 \\
\hline & Total & 3686 & 1.96 & 0.00 & 26.76 \\
\hline
\end{tabular}

the three comparisons $(p<0.001)$.

Age-dependent alteration of the mercury levels showed a similar feature through the five districts as shown in Fig. 2. The male levels increase in an age-dependent manner up to 50's or 60's, whereas further aged generations showed somewhat lower levels. On the other hand, the age-dependent alteration in female levels was not so marked as in males, especially in certain populations such as Minamata and Kumamoto (Figs. 2a and 2b). Interestingly, the female levels showed a transient reduction at 20' $\mathrm{s}$, which was not shown in the males. The sexual difference became apparent at ages older than twenty.

The average mercury level of the hair sample varied from 2.23 to $4.79 \mu \mathrm{g} / \mathrm{g}$ for males and from 1.23 to $2.50 \mu \mathrm{g} / \mathrm{g}$ for females among the different sampling sites (Table 1). The geometric mean was significantly higher in Chiba, $4.79 \mu \mathrm{g} / \mathrm{g}$ in males and $2.30 \mu \mathrm{g} / \mathrm{g}$ in females, than in the others $(\phi<0.001)$. The age dependent distribution profile obtained in Chiba, as in Fig. 2e, was slightly different from those of the other four sampling sites representing a relatively higher exposure level to methylmercury in most age classes of Chiba. Table 2 indicated the results of multiple regression analysis. The analysis revealed that the mercury content was significantly correlated with several covariates such as sex, age, the amount of daily intake of total fish/shellfish, tendencies of eating certain fish including tuna or bonito, and artificial waving $(p<0.001)$. A residence site in Chiba was still one of the significant determinants for hair mercury level even after the adjustment of these six variables.

Table 3 indicates the cumulative frequency of the individual hair mercury content among the total population. About half of the population possessed hair mercury contents that exceed $2 \mu \mathrm{g} / \mathrm{g}$, and about $1 / 10$ of males and less than $4 \%$ of females exceeded $5 \mu \mathrm{g} / \mathrm{g}$. On the other hand, only $17 \%$ of the total population, 

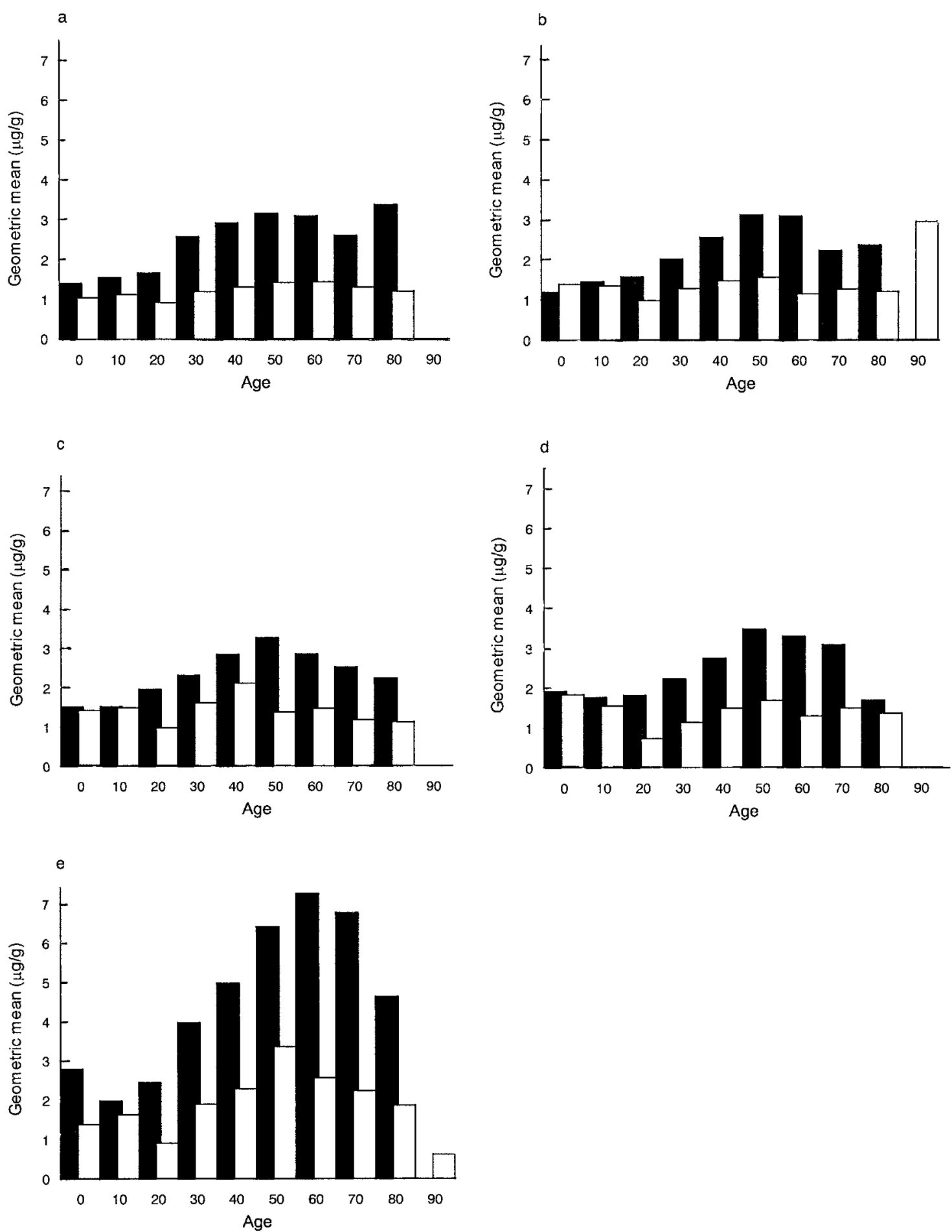

Fig. 2. Age dependent distribution of the geometric mean of the hair mercury content in Minamata (a), Kumamoto (b), Tottori (c), Wakayama (d) and Chiba (e). Open bar and solid bar indicate female and male populations, respectively.

口, Male; $\square$, Female. 
TABLE 2. Factors that determine the hair mercury content as a dependent variable by a multiple regression analysis

\begin{tabular}{lccc}
\hline \multicolumn{1}{c}{ Independent variables } & $\begin{array}{c}\text { Standardized partial } \\
\text { regression coefficient }\end{array}$ & $\begin{array}{c}\text { Partial correlation } \\
\text { coefficient }\end{array}$ & $\begin{array}{c}\text { Multiple correlation } \\
\text { coefficient }\end{array}$ \\
\hline Sex & 0.162 & 0.170 & \\
Age & 0.264 & 0.352 & \\
Daily amount of total fish/ & 0.190 & 0.245 & \\
shellfish consumed & -0.185 & -0.252 & 0.585 \\
Artificial hair waving & & & \\
Usually consumed fish & 0.058 & 0.167 & \\
$\quad$ Tuna: & 0.063 & 0.068 & \\
$\quad$ Bonito & & 0.242 & \\
Residence & 0.281 & & \\
$\quad$ Chiba & &
\end{tabular}

TABLE 3. Cumulative frequency of the individual hair mercury content

\begin{tabular}{|c|c|c|c|c|c|c|c|}
\hline \multirow{2}{*}{ Sex } & \multirow{2}{*}{ Age } & \multicolumn{5}{|c|}{ Mercury concentration $(\mu \mathrm{g} / \mathrm{g})$} & \multirow{2}{*}{ Total } \\
\hline & & $\leqq 1$ & $\leqq 2$ & $\leqq 3$ & $\leqq 5$ & $\leqq 10$ & \\
\hline \multirow[t]{4}{*}{ Female } & All & 464 & 1161 & 1473 & 1612 & 1659 & 1666 \\
\hline & & $(27.9 \%)$ & $(69.7 \%)$ & $(88.4 \%)$ & $(96.8 \%)$ & $(99.6 \%)$ & $(100 \%)$ \\
\hline & $15-49$ & 200 & 453 & 542 & 577 & 585 & 588 \\
\hline & & $(34.0 \%)$ & $(77.0 \%)$ & $(92.2 \%)$ & $(98.1 \%)$ & $(99.5 \%)$ & $(100 \%)$ \\
\hline \multirow[t]{2}{*}{ Male } & All & 162 & 724 & 1206 & 1716 & 1975 & 2020 \\
\hline & & $(8.0 \%)$ & $(35.8 \%)$ & $(59.7 \%)$ & $(85.0 \%)$ & $(97.8 \%)$ & $(100 \%)$ \\
\hline \multirow[t]{2}{*}{ Total } & All & 626 & 1885 & 2679 & 3328 & 3634 & 3686 \\
\hline & & $(17.0 \%)$ & $(51.1 \%)$ & $(72.7 \%)$ & $(90.3 \%)$ & $(98.6 \%)$ & $(100 \%)$ \\
\hline
\end{tabular}

$28 \%$ of females and $8 \%$ of males, had hair mercury levels below the EPA-recommended 1 $\mu \mathrm{g} / \mathrm{g}$. On the subsample of reproductive aged females (15 to 49 years of age), $66 \%$ of the participants exceeded the EPA/recommended level, and approximately $2 \%$ was above $5 \mu \mathrm{g} / \mathrm{g}$. It was also found that the hair levels of small portions of the subject population, $0.4 \%$ females for example, were more than $10 \mu \mathrm{g} / \mathrm{g}$, which is a critical hair mercury level with possible adverse effects on a developing fetus in utero (NRC 2000).

The lower levels in the adult females might be partly due to artificial hair waving. A frequency of the hair waving above 20's in each district was about five folds higher in females
(44.6 to $68.7 \%$ ) than males (8.4 to $17.1 \%$ ). Yamamoto and Suzuki (1978) demonstrated that thioglycolate in the artificial waving lotion effectively removed hair mercury. To make sure we treated hair samples from non-artificial hair waved women up to 3 times with waving lotions that were commonly used in Japanese beauty saloons. More than $30 \%$ of the hair mercury was removed by a single treatment of the lotions (Fig. 3). Repeated treatments further removed the hair mercury. Removal of a portion of hair mercury was evident also from the longitudinal hair analysis of whole hair samples from female Minamata citizens. The typical features for waved and non-waved hairs were shown in Fig. 4. The levels at the root of 


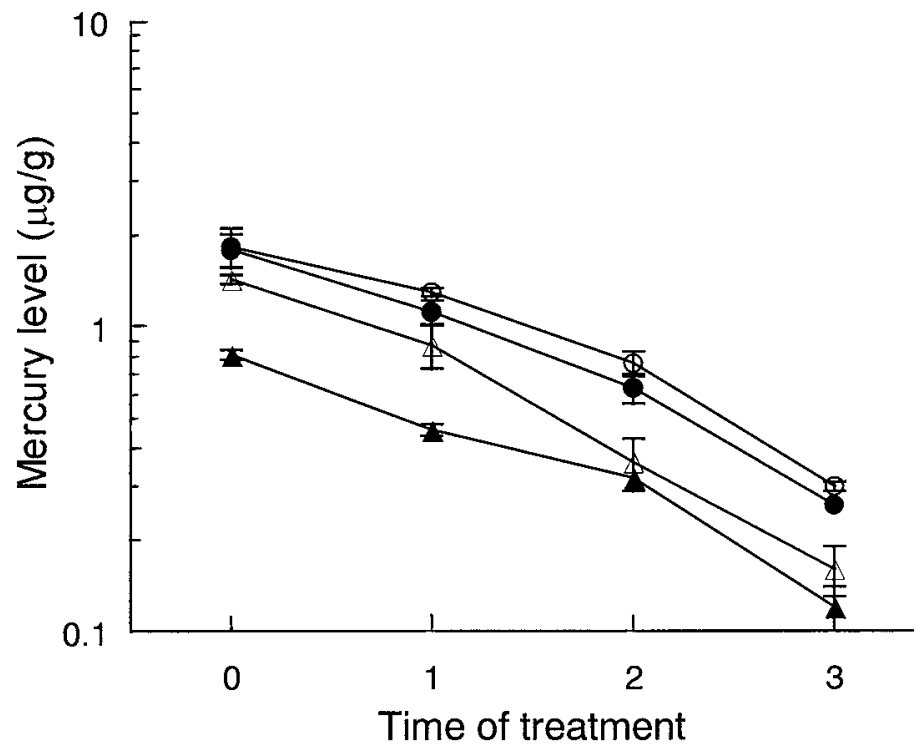

Fig. 3. Effect of artificial waving on hair mercury levels. Non/artificial permanent waved hair samples from 4 women (A to D) were treated with waving lotion up to 3 times. Hair mercury levels were determined after each treatment. Each value represent the mean \pm s.D. of 3 measurements.

○, $\mathrm{A} ; \boldsymbol{\mathbf { A }}, \mathrm{B} ; \triangle \mathrm{\triangle}, \mathrm{C} ; \ominus, \mathrm{D}$.

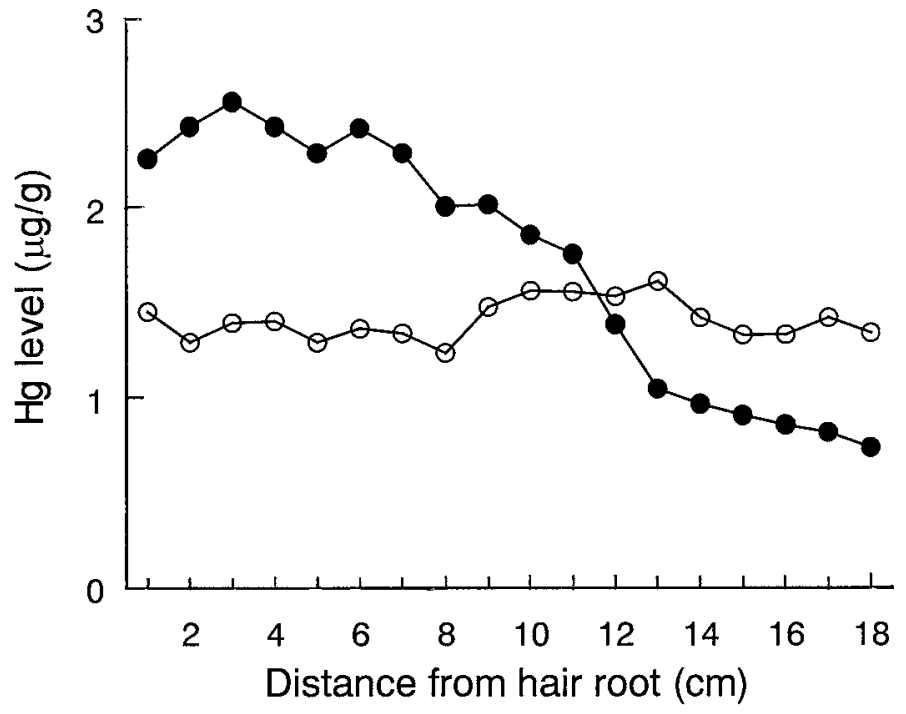

Fig. 4. Whole length analysis of hair mercury levels. Mercury levels of whole hair strands from two women (with and without artificial permanent waving) were analyzed at $1-\mathrm{cm}$ sections. $\ominus$, waving (-); $\mathbf{0}$, waving $(+)$.

the artificially waved hair were significantly higher than those at the tip $(\phi<0.001)$ (Table 4$)$. On the other hand, the difference was not significant between the two sides of the nonwaved hairs.

\section{DISCUSSION}

The present study has been conducted to obtain information on hair mercury levels in the general population of Japan as reference data 
TABle 4. Ratio of hair mercury levels at the hair tip to the root in female Minamata citizens

\begin{tabular}{ccc}
\hline Artificial waving & No (38) & Yes (98) \\
\hline Hg Ratio: Tip/Root & $0.92 \pm 0.21$ & $0.56 \pm 0.22$ \\
\hline
\end{tabular}

Numbers of hair samples are shown in parentheses

for estimating standard exposure levels of methylmercury mainly through the dietary fish/ shellfish consumption. The survey is still continuing to expand the subject population while the present paper showed the preliminary results on the data obtained in the first five sampling sites. Average hair mercury levels were estimated to be 1.43 and $2.55 \mu \mathrm{g} / \mathrm{g}$, as geometric means, for female and male populations, respectively. These levels are relatively higher than the levels estimated from blood or toenail mercury concentrations recently observed in several western countries (Sanzo et al. 2001; Guallar et al. 2002; CDC 2003). It can be considered that the difference mainly originated from the different food consumption habits among populations. The implications of the present results will be discussed in detail elsewhere from a viewpoint of risk management of the low level methylmercury exposures.

The participants of this survey were volunteers and did not associate with any physical complaints, and the hair mercury levels obtained could be considered as a general population level in Japan. However, there might be some limitations on the interpretation of the results. Because the survey was conducted without random sampling, selection bias may exist. Alternatively, the present results indicated that the hair mercury level varied among the population of different districts. Chiba, for example, was a significant factor that increased the hair mercury level even after adjustment for the other main confounders such as age, sex, amount of fish/shellfish consumption and the tendency to consume certain fish species. It is not clear what kinds of characteristics are associated with the regional difference observed. It might be plausible that there were dietary habits which were failed to be surmised by the questionnaire used in this study. In any case, it should be pointed out, based on the present results, that the selection of the sampling site is one of the most important factors in the stratification for sample collection on a population survey aiming at the evaluation of general exposure level for methylmercury.

The second issue is the effects of the artificial waiving on hair mercury concentration. It may sometimes result in a more serious problem for hair mercury assessment on the general population, because the individual hair mercury content might be reduced by as much as $50 \%$ after the artificial treatment. In the present survey, 25\% reductions were observed on the geometric mean of the mercury level, if the hair sample had been collected from participants with waving treatment in both sexes. Thus, analysis of the hair root would be preferable to estimate the exact mercury exposure level for individuals.

The present hair mercury data would reflect a portion of the food habits of the current Japanese population. Although it was suggested that a large proportion of the Japanese population is exposed to methylmercury at doses over the EPA/NRC recommended level through the daily intake of fish/shellfish, this does not necessarily imply that they are exposed to doses with a substantial hazard to a fetus. However, a very little portion $(0.4 \%)$ of females at the reproductive ages, that showed hair mercury levels above $10 \mu \mathrm{g} / \mathrm{g}$, may have to change the amount or species of fish consumed in their daily life concerning pregnancy to avoid possible adverse effects on a developing fetus. The results of the present study should be helpful to establish a healthy diet with an appropriate consumption of fish and shellfish, which are nutritionally outstanding foods containing valuable nutrients such as n-3 polyunsaturated 
fatty acids.

\section{Acknowledgment}

The authors thank Ms. M. Ogata, Ms. N. Ogata, Ms. A. Hyodo and Ms. Y. Miyamato for their technical assistance in processing the hair samples and mercury analysis.

\section{References}

Cox, C., Clarkson, T.W., Marsh, D.O., Amin-Zaki, L., Tikriti, S. \& Myers, G.G. (1989) Doseresponse analysis of infants prenatally exposed to methylmercury. An application of a single compartment model to singlestrand hair analysis. Environ. Res., 49, 318332.

Guallar, E., Sanz-Gallardo, M.I., van't Veer, P., Bode, P., Aro, A., Gomez-Aracena, J., Kark, J.D., Riemersma, R.A., Martin-Moreno, J.M. \& Kok, F.J. (2002) Mercury, fish oils, and the risk of myocardial infarction. New Engl. J.
Med., 347, 1747-1754.

National Research Council. Committee on the Toxicology Effects of Methylmercury (2000) Toxicological Effects of Methylmercury, National Academy Press, Washington DC.

Sanzo, J.M., Dorronsoro, M., Amiano, P., Aguinagalde, F.X. \& Azpiri, M.A. (2001) Estimation and validation of mercury intake associated with fish consumption in an EPIC cohort of Spain. Public Health Nutr., 4, 981988.

The Centers for Disease Control and Prevention, United States (2003) Second National Report on Human Exposure to Environmental Chemicals.

EPA (1997) Mercury Study Report to Congress., Washington, D.C., United States Environmental Protection Agency.

WHO (1990) IPCS Environmental Health Criteria 101 Methylmercury. World Health Organization, Geneva.

Yamamoto, R. \& Suzuki, T. (1978) Effects of artificial hair/waving on hair mercury values. Int. Arch. Occup. Environ. Health, 42, 1-9. 